\title{
PREVALENCE OF POST STROKE DEPRESSION IN AMBULATORY PATIENTS
}

\author{
Valentina Asabella $^{1 *}$, Mira Rakacolli ${ }^{2}$ \\ ${ }^{*}$ Community Center of Mental Health, No. 3, Tirana, Albania: \\ ${ }^{2}$ University Hospital Centre "Mother Theresa”, Neuro-Psychiatric Service, Tirana, Albania;
}

*Corresponding author Valentina Asabella, email: valentinaqemalli@yahoo.com;

Received May, 2018; Accepted May, 2018; Published June, 2018;

DOI: https://doi.org/10.31407/ijees8318

UOI license: http://u-o-i.org/1.01/ijees/44039819

\begin{abstract}
Depression and humor change is a common and serious complication after cerebrovascular disease that may affect functional recovery and quality of life of patients. The purpose of the study is to assess the prevalence of depression after the stroke. This is a prospective study involving 183 patients aged 46-81 with stroke after hospitalization attending the Community Center for Mental Health in Tirana during 2012-2015. Depression was diagnosed by DSM-IV and DUI-II criteria. DASS-42 was also used for assessing symptoms of depression, anxiety and stress. The average age of the total patient is $65.8( \pm 6.8)$ years (range 46-81 years). $31.7 \%$ of patients were female and most of them (68.3\%) males. The highest frequency of depression is after 6 months $(23.5 \%)$ of patients (95\% CI $17.94-$ 30.14); A significant trend of increasing the prevalence of depression has been found with increasing educational level and lowering the economic level $(\mathrm{p}<0.01)$. Concerning medical history: Diabetes is an independent risk factor for hitting [OR $=2.4195 \%$ CI $1.32-13.41 \mathrm{p}=0.02]$. Of the Severity Assessment according to DUI-II with mild depression resulted $(2.7 \%)$ of patients with moderate depression $(6.6 \%)$ patients while severe-onset 26 patients (14.2\%) prevailed. Given the negative impact of PSD, early detection and interference are important. Clinical implications are close observation of stroke and depression patients, especially during the first 3 months of the stroke and those with risk factors for PSD.
\end{abstract}

Key words: cerebrovascular disease, depression, risk factors 